TOM IX (2018)

\author{
Michał Dalidowicz \\ (Wydział Historyczny, Uniwersytet Jagielloński)
}

\title{
Perspektywa badań epigraficznych a koncepcja zarządzania informacją
}

Epigrafika, jako jedna z dziedzin pomocniczych w badaniach historycznych, na arenie Polski funkcjonuje od lat siedemdziesiątych ubiegłego wieku. Józef Szymański był pierwszym polskim naukowcem, który zwrócił uwagę na wartość inskrypcji występujących w innym kontekście niż dokument. Sama epigrafika zajmuje się bowiem poszukiwaniem, odczytem, a także analizą napisów wykonanych w twardym materiale (kamień, metal, brąz, drewno), jak również malowanych oraz wyszywanych ${ }^{1}$.

Przez blisko czterdzieści ostatnich lat prowadzono inwentaryzacje inskrypcji na terenie całej Polski. Owocem tych terenowych poszukiwań jest Corpus inscriptionum Poloniae ${ }^{2}$. W ciągu tego czasu ukazało się dziesięć tomów po kilka zeszy-

1 Adam Górski, „Wprowadzenie”, w Inskrypcje kościoła św. Elżbiety we Wrocławiu w świetle rękopisu z 1649 roku, oprac. Janusz Gołaszewski, Górski (Wrocław: Eternum, 2016), 17.

2 Corpus inscriptionum Poloniae, t. 1, Województwo kieleckie, red. Józef Szymański, z. 1, Miasto Kielce i powiat kielecki, wyd. Barbara Trelińska (Kielce: Muzeum Świętokrzyskie, 1975); z. 2, Jędrzejów i region jędrzejowski, wyd. Trelińska (Kielce: Muzeum Świętokrzyskie, 1978); z. 3, Busko-Zdrój i region, wyd. Urszula Zgorzeliska (Kielce: Muzeum Świętokrzyskie, 1980); z. 4, Miechów i Pińczów wraz z regionem, wyd. Trelińska (Kielce: Muzeum Świętokrzyskie 1983); z. 5, Włoszczowa, końskie i Ostrowiec Świętokrzyski z regionami, wyd. Maciej Janik (Kielce: Muzeum Świętokrzyskie, 1986); t. 2, Województwo sieradzkie, red. Ryszard Rosin, wyd. Alicja Szymczak, Jan Szymczak (Warszawa-Łódź: Państwowe Wydawnictwo Naukowe, 1981); t. 3, Województwo miejskie łódzkie, red. Rosin, wyd. Alicja Szymczak i Jan Szymczak (Warszawa-Łódź: Państwowe Wydawnictwo Naukowe, 1982); t. 4, Województwo włocławskie, z. 1, Kujawy Brzeskie, wyd. Andrzej Mietz, Jan Pakulski (Włocławek-Toruń: MZKiD, 1985); z. 2, Ziemia Dobrzyńska, wyd. Mietz, Pakulski (WłocławekToruń: MZKiD, 1987); z. 2, Suplement, oprac. Mietz (Rypin: MZKiD, 1995); t. 5, Województwo skierniewickie, red. Rosin, z. 1, Skierniewice i region, wyd. Alicja Szymczak (Warszawa-Łódź: Państwowe Wydawnictwo Naukowe, 1991); z. 2, Miasto Łowicz, wyd. Jan Szymczak (Warszawa-Łódź: Państwowe Wydawnictwo Naukowe, 1987); t. 6, Województwo piotrkowskie, wyd. Jan Szymczak (Łódź-Piotrków Trybunalski: Polskie Towarzystwo Historyczne, 1993); t. 7, Województwo radomskie, red. Zenon Guldon, z. 1, Radom i Iłża wraz z powiatem, wyd. Waldemar Kowalski (Warszawa: Wydawnictwo PAE, 1992); t. 8, Województwo krakowskie, red. Zbigniew Perzanowski, z. 1, Katedra 
tów każdy. Wśród epigrafików, którzy swoją pracę naukową poświęcili badaniom inskrypcji w materiale twardym, należy wymienić Barbarę Trelińską, która zajmowała się województwem kieleckim, Ryszarda Rosina oraz Jana i Alicję Szymczaków - redaktorów tomu sieradzkiego oraz łódzkiego, Zbigniewa Perzanowskiego i Zenona Piecha - redaktorów edycji krakowskiej, a także Joachima Zdrenkę, redaktora tomu lubuskiego. Ponadto warto wspomnieć o znakomitej pracy pani profesor Trelińskiej Gotyckie pismo epigraficzne w Polsce $e^{3}$. Jest to dzieło o tyle ważne, że traktuje inskrypcje epigraficzne względem pisma i narzędzi jego wykonania, a nie samej treści. Bardzo ważnym dziełem dla poznania oraz zrozumienia inskrypcji jest także seria wydawnicza Die Deutschen Inschriften. To wielotomowe dzieło przedstawia inskrypcje zebrane na terenie Niemiec. Wydaje się również, iż jest to punkt wyjścia dla analizy porównawczej inskrypcji zebranych na terenie Polski w stosunku do tych niemieckich.

Wśród naukowców zajmujących się zagadnieniem inskrypcji należy wymienić badaczy ośrodka lubuskiego - Adama Górskiego, Pawła Karpa oraz Marcelego Tureczka, którzy opracowywali zeszyty lubuskiego CiP. Należy również wspomnieć o poznańskich naukowcach, Edwardzie Skibińskim oraz Pawle Stróżyku, a także głównym spiritus movens epigrafiki na Uniwersytecie Gdańskim - Krzysztofie Macieju Kowalskim (Artefakty jako źródło poznania, Inskrypcje na dzwonach gotyckich w Prusach. Studium z epigrafiki kampanologicznej, Dawne inskrypcje pomorskie. Studia epigraficzne) $)^{4}$. Jego studia nad inskrypcjami Prus oraz Pomorza niewątpliwie stanowią ogromny wkład w spuściznę epigraficzną nauki polskiej.

krakowska na Wawelu, red. Roman M. Zawadzki, wyd. Agnieszka Perzanowska (Kraków: Unum, 2002); z. 2, Bazylika mariacka w Krakowie, wyd. Zenon Piech (Kraków: Polskie Towarzystwo Teologiczne, 1987), z. 6, Kazimierz i Stradom, wyd. Zbigniew Wohlfeld (Kraków: Nasza Przeszłość, t. 72, 1989); t. 9, Województwo olsztyńskie, z. 1, Lubawa i okolice, wyd. Jarosław Wenta i Jan Wroniszewski (Toruń: Wydawnictwo Uniwersytetu Mikołaja Kopernika, 1995); t. 10, Województwo lubuskie, red. Joachim Zdrenka, z. 1, Inskrypcje powiatu międzyrzeckiego do 1815 roku, wyd. Marceli Tureczek (Toruń: Wydawnictwo Adam Marszałek, 2006), z. 2, Powiat wschowski, wyd. Górski, Paweł Karp (Toruń: Wydawnictwo Adam Marszałek, 2006), z. 3, Powiat świebodziński, wyd. Tureczek (Toruń: Wydawnictwo Adam Marszałek, 2009), z. 4, Powiat nowosolski: lapidaria w Bytomiu Odrzańskim i Kożuchowie, wyd. Górski (Toruń: Wydawnictwo Adam Marszałek, 2009), z. 5, Powiat zielonogórski, wyd. Górski, Karp (Toruń: Wydawnictwo Adam Marszałek, 2012), z. 6, Powiat nowosolski, wyd. Górski (Toruń: Wydawnictwo Adam Marszałek, 2013), z. 7, Miasto i powiat Gorzów Wielkopolski, wyd. Zdrenka (Toruń: Wydawnictwo Adam Marszałek, 2015); z. 8, Powiat Krosno Odrzańskie (do 1815 roku), wyd. Zdrenka (Toruń: Wydawnictwo Adam Marszałek, 2016), z. 9, Powiat Sulęciński (do 1815 roku), wyd. Tureczek (Toruń: Wydawnictwo Adam Marszałek, 2017).

3 Trelińska, Gotyckie pismo epigraficzne w Polsce (Lublin: Wydawnictwo Uniwersytetu Marii Curie-Skłodowskiej, 1991).

4 Krzysztof M. Kowalski, Artefakty jako źródła poznania: studium z teorii nauki historycznej (Gdańsk: Wydawnictwo Uniwersytetu Gdańskiego, 1996); Dawne inskrypcje pomorskie: studia epigraficzne (Gdańsk: Wydawnictwo Uniwersytetu Gdańskiego, 2001); Inskrypcje na dzwonach gotyckich w Prusach: studium z epigrafiki kampanologicznej (Gdańsk: Wydawnictwo Uniwersytetu Gdańskiego, 2006). 
Inskrypcje analizowane przez wspomnianych już badaczy należą do grupy napisów łacińskich (pisanych alfabetem łacińskim w języku polskim, łacińskim oraz niemieckim). W Polsce znajdują się także inskrypcje w alfabecie hebrajskim. Pierwszym badaczem tych napisów był Marcin Wodziński, którego praca Hebrajskie inskrypcje na Śląsku XIII-XVIII wieku stała się kamieniem węgielnym hebrajskiej epigrafiki w Polsce ${ }^{5}$. Po nim temat ten podjęli Leszek Hońdo (Hebrajska epigrafika nagrobna w Polsce ${ }^{6}$ ) z Uniwersytetu Jagiellońskiego oraz Andrzej Trzciński (Hebrajskie inskrypcje na materiale kamiennym $w$ Polsce w XIII-XX wieku. Studium paleograficzno-epigraficzne ${ }^{7}$ ) z Uniwersytetu im. Marii Curie-Skłodowskiej, którzy poszerzyli zakres badań nad hebrajskimi inskrypcjami o ich analizę oraz wyjaśnienie sfery symbolicznej.

Inskrypcje badane przez polskich naukowców znajdują się również poza współczesnymi granicami Polski. Jednym z najwybitniejszych badaczy napisów na terenie dawnej Rzeczypospolitej jest Wojciech Drelicharz (Pomniki epigrafiki i heraldyki dawnej Rzeczypospolitej na Ukrainie; Inskrypcje polskich grobów na cmentarzach Podola $)^{8}$. Prace inwentaryzacyjne pod jego kierownictwem przyniosły wiele publikacji przedstawiających efekty tych badań terenowych, a które niewątpliwie stanowią ogromny wkład w poznanie epigraficznego krajobrazu Rzeczypospolitej. Pozostając przy terenach kresowych, warto również wspomnieć pozycję Zabytkowe cmentarze na kresach wschodnich Drugiej Rzeczypospolitej, pod redakcją Anny i Jacka Lewkowskich oraz Wojciecha Walczaka9.

5 Marcin Wodziński, Hebrajskie inskrypcje na Śląsku XIII-XVIII wieku (Wrocław: Towarzystwo Przyjaciół Polonistyki Wrocławskiej, 1996).

6 Leszek Hońdo, Hebrajska epigrafika nagrobna w Polsce (Kraków: TAiWPN Universitas, 2014).

7 Andrzej Trzciński, Hebrajskie inskrypcje na materiale kamiennym w Polsce w XIII-XX wieku. Studium paleograficzno-epigraficzne (Lublin: Wydawnictwo Uniwersytetu Marii Curie-Skłodowskiej, 2007).

8 Inskrypcje polskich grobów na cmentarzach Podola, t. 1, Czerwonogród, Jagielnica, Jazłowiec, Kupin, Mielnica Podolska, Międzybóż, Salówka, Stara Sieniawa, Zaleszczyki, red. Wojciech Drelicharz (Kraków: Wydawnictwo Towarzystwa Naukowego „Societas Vistulana” 2004); Pomniki epigrafiki i heraldyki dawnej Rzeczypospolitej na Ukrainie, t. 1, Ziemia lwowska dawnego województwa ruskiego, red. Drelicharz, oprac. Agnieszka Biedrzycka (Kraków: Wydawnictwo Towarzystwa Naukowego "Societas Vistulana” 2005); Pomniki epigrafiki i heraldyki dawnej Rzeczypospolitej na Ukrainie, t. 2, Dawne województwo podolskie, red. Drelicharz, oprac. Piotr Kuliszewicz (Kraków: Wydawnictwo Towarzystwa Naukowego "Societas Vistulana” 2005); Pomniki epigrafiki i heraldyki dawnej Rzeczypospolitej na Ukrainie, t. 3, Ziemia przemyska dawnego województwa ruskiego, red. Drelicharz, oprac. Andrzej Marzec (Kraków: Wydawnictwo Towarzystwa Naukowego „Societas Vistulana" 2008); Pomniki epigrafiki i heraldyki dawnej Rzeczypospolitej na Ukrainie, t. 4, Kamieniec Podolski, red. Drelicharz, oprac. Piotr Rabiej (Kraków: Wydawnictwo Towarzystwa Naukowego „Societas Vistulana” 2009).

9 Anna Lewkowska, Jacek Lewkowski, Wojciech Walczak, Zabytkowe cmentarze na Kresach Wschodnich Drugiej Rzeczypospolitej: województwo wileńskie na obszarze Republiki Białorusi (Warszawa: Wydawnictwo DiG, 2007); iidem, Zabytkowe cmentarze na Kresach Wschodnich Drugiej Rzeczypospolitej: wschodnie powiaty dawnego województwa białostockiego (obecnie na terenie Białorusi) (Warszawa: Wydawnictwo DiG, 2007); iidem, Zabytkowe cmentarze na Kresach Wschodnich Drugiej Rzeczypospolitej: województwo nowogródzkie (Warszawa: Wydawnictwo DiG, 2008). 
Kwestię nagrobków gotyckich, a zatem również inskrypcji, podjął w swojej pracy Przemysław Mrozowski (Polskie nagrobki gotyckie) ${ }^{10}$, gdzie umieścił zestawienie nagrobków z terenów Rzeczpospolitej w przededniu wojny trzydziestoletniej. Jest to korpus pomników istniejących oraz nieistniejących, znanych wyłącznie ze źródeł pisanych.

Badania śląskich epigrafów podjęte przez Bogusława Czechowicza przyniosły ważną publikację Nagrobki późnogotyckie na Śląsku ${ }^{11}$. Dzieło to jest o tyle istotne, że uzupełnia inwentarz epigraficzny o inskrypcje z terenu Śląska. Co więcej, zainteresowania naukowe profesora Czechowicza, jako historyka sztuki, dały efekt w postaci niemalże kompletnego przedstawienia elementów ozdobnych oraz ich symboliki. Obok wspomnianych już badaczy warto również zwrócić uwagę na prace profesora Jana Harasimowicza. Ten wrocławski naukowiec zajmujący się historią sztuki nowożytnej Śląska zinwentaryzował śląskie nagrobki wieku reformacji, zwracając szczególną uwagę na epitafia (Mors janua vitae: Śląskie epitafia i nagrobki wieku reformacji ${ }^{12}$ ).

Na terenie województwa lubuskiego prace inwentaryzacyjne prowadził również Wojciech Krawczuk. Opublikowane w 1999 r. Niemieckie inskrypcje w Polsce. Deutsche Inschriften in Polen. T. I. Kożuchów Freystadt są nie tylko pozycją istotną z punktu widzenia dokumentacji epigraficznej, ale również jest to swoisty kamień węgielny położony pod epigrafikę lubuską ${ }^{13}$.

Wśród lubelskich badaczy należy wymienić także Pawła i Katarzynę Madejskich, którzy będąc uczniami profesorów Szymańskiego i Trelińskiej kontynuują ich dzieło w sferze badań epigraficznych, pozostając jednymi z niewielu aktywnie działających epigrafików w Polsce.

Epigrafika umożliwia również poznanie źródeł dotyczących życia doczesnego społeczeństw okresu nowożytności. Pozycja Katarzyny Góreckiej jest tego dobrym przykładem (Pobożne matrony i cnotliwe panny. Epitafia jako źródło wiedzy o kobiecie w epoce nowożytnej) ${ }^{14}$.

Co łączy powyższe i dlaczego aż tyle miejsca zostało poświęcone na informacje o tych badaczach? Wspólnym mianownikiem, a jednocześnie elementem różnicującym, jest epigrafika. Każda z powyższych osób inskrypcjami zajmuje się zawodowo bądź w ramach swoich zainteresowań badawczych. Ponadto wszystkie wymienione wyżej pozycje książkowe zawierają inwentarze epigraficzne, czasami w towarzystwie pełnej analizy naukowej, czasami tylko z niektórymi jej

10 Przemysław Mrozowski, Polskie nagrobki gotyckie (Warszawa: Arx Regia, 1994).

11 Bogusław Czechowicz, Nagrobki późnogotyckie na Śląsku (Wrocław: Wydawnictwo Uniwersytetu Wrocławskiego, 2003).

12 Jan Harasimowicz, Mors janua vitae. Śląskie epitafia i nagrobki wieku reformacji (Wrocław: Wydawnictwo Uniwersytetu Wrocławskiego, 1992).

13 Niemieckie inskrypcje w Polsce: Dolny Śląsk, t. 1, Kożuchów (Freystadt): epitafia z muru i kaplic starego cmentarza ewangelickiego, oprac. Wojciech Krawczuk (Kożuchów-Kraków: Zamek, Oficyna Cracovia, 1999).

14 Katarzyna Górecka, Pobożne matrony i cnotliwe panny. Epitafia jako źródło wiedzy o kobiecie w epoce nowożytnej (Warszawa: Neriton, 2006). 
elementami. Co więc je różni? Co jest problemem w tych badaniach? Ich całkowite rozproszenie w nauce polskiej. Badania mające ten sam cel, oparte na podobnych ideach, przedstawiają wnioski i wyniki często w różny od siebie sposób; nie są ujednolicone. Wydawać by się mogło, że seria Corporis inscriptionum Poloniae będzie tym jednolitym, wypracowanym monumentem wiedzy o epigrafice w Polsce, jednakże poszczególne tomy różnią się w przedstawieniu wyników badań. Niektóre $\mathrm{z}$ informacji zawartych $\mathrm{w}$ tych publikacjach są nieczytelne i niezrozumiałe dla osoby niezajmującej się epigrafiką zawodowo. Nawet badacz korzystający z całości zebranego materiału, zmuszony jest dokonać selekcji oraz pogrupowania zgromadzonych informacji, by wydobyć jasny i przejrzysty wzór, zawarty w zestawieniu inskrypcji. Naturalnym wydaje się fakt, że owe zbiory są czystą edycją źródłową, charakterystyczną dla tego typu publikacji z lat siedemdziesiątych. Ramy czasowe, zakres terytorialny, a także przedmioty, na których występują inskrypcje, determinują ostateczny kształt omawianych publikacji.

Gdyby więc przyjąć, że badacze zajmujący się naukami społecznymi, wykorzystujący wyniki badań epigraficznych, będą określoną społecznością, zostaną zalani natłokiem informacji o inskrypcjach. Chaos panujący w zakresie całej epigrafiki powinien więc zostać uporządkowany, a "szum informacyjny”, rozumiany jako zbędne metadane znajdujące się w poszczególnych publikacjach, usunięty. Innymi słowy, potrzebna jest regulacja formy przedstawienia zapisu tych informacji, a także dbałość o ich swobodny przepływ ${ }^{15}$. Remedium na wskazane powyżej bolączki może stanowić zarządzanie wiedzą. Jak zaznacza Marzena Świgoń, dotyczy ono szerokich kompetencji i postaw jednostek, podnoszących ich efektywność w środowisku prywatnym, organizacyjnym i społecznym ${ }^{16}$. By przekuć poszczególne informacje $\mathrm{w}$ wiedzę, należałoby zebrany materiał poddać kompleksowemu przetworzeniu naukowemu. By tego jednak dokonać, materiał gromadzony przez wielu epigrafików powinien być skupiony w jednym miejscu, w ujednoliconej postaci i w równej formie dostępny dla każdego.

Niech więc punktem wyjścia tych rozważań będzie „zasób”. Katarzyna Materska scharakteryzowała go jako pewną ilość czegoś, co zostało już zebrane, zgromadzone w konkretnym celu, do wykorzystania w przyszłości ${ }^{17}$. Przez wiele lat prowadzono

15 Lech W. Zacher, „Od społeczeństwa informacyjnego do społeczeństwa wiedzy (dylematy tranzycyjne: między informacją, wiedzą i wyobraźnią)”, w Społeczeństwo informacyjne. Wizja czy rzeczywistość?, t. 1, red. Lesław H. Haber (Kraków: AGH Uczelniane Wydawnictwa Naukowo-Dydaktyczne, 2014), 106.

16 Marzena Świgoń, Personal Knowledge Management. Indywidualne zarządzanie wiedza, 2009. Referat wygłoszony podczas Xth National Forum for Scientific and Technical Information 22-25 września 2009 w Zakopanem. Dostęp online: http://eprints.rclis.org/13854/1/Marzena\%C5\%9Awigo\%C5\%84.Personal_Knowledge_Management.pdf, dostęp: 7 VII 2018.

17 Katarzyna Materska, „Rozwój koncepcji wiedzy jako zasobu organizacji”, w Od informacji naukowej do technologii społeczeństwa wiedzy, red. Barbara Sosińska-Kalata i Maria Przastek-Samokowa (Warszawa: Wydawnictwo Stowarzyszenia Bibliotekarzy Polskich, 2005), 201. 
badania epigraficzne. Wyniki wielu z nich zostały opublikowane w edycjach źródłowych, pozycjach monograficznych albo są rozproszone w artykułach zamieszczonych w czasopismach naukowych. Jednakże mnóstwo zebranych inskrypcji, często obecnie już zaginionych, pozostaje w rękach prywatnych naukowców, ponieważ nie było możliwości, czasu bądź pieniędzy, by je opublikować. Sama epigrafika, obok sfragistyki, genealogii czy heraldyki, wypada więc nieco blado w świetle prowadzonych badań, a także wykorzystania ich wyników w pisarstwie historycznym.

Wiedza jest niejako zorganizowaną kombinacją myśli, zasad, procedur, a także informacji. I tak samo jak student, zdobywając wiedzę, sięga do różnych kompendiów kompleksowo gromadzących informacje, tak historyk sięga po różne materiały źródłowe ${ }^{18}$. W przypadku epigrafiki wydaje się, że nadal jest to nieco utrudnione.

Jason Frand i Aura Lippincott zwracają uwagę na cztery schematy definiujące problem przeciążenia informacyjnego ${ }^{19}$. Według pierwszego z nich ogromna ilość informacji na dany temat okaże się niewystarczająca, gdy poszczególne informacje będą wyselekcjonowane indywidualnie i według własnych wartości. Przekładając to na problem epigraficzny, rozproszony materiał źródłowy, nawet jeśli zgromadzony jednocześnie, nie przyniesie oczekiwanych rezultatów ze względu na swoje zróżnicowanie w przedstawieniu wyników badań. Przykładem niech będą poszczególne tomy $\mathrm{CiP}$ i rozbieżności w prezentacji inskrypcji. Innymi słowy, ujednolicenie wartościujące zebranych epigrafów mogłoby zmniejszyć ryzyko przeoczenia ważnych danych, wykluczenia ich, a przede wszystkim mogłoby skrócić czas pracy nad danym materiałem źródłowym.

Według drugiego schematu, problemem okazują się informacje niepotrzebne, niezamawiane czy nierelewantne do danego zbioru. W tym miejscu ukłon należy się historykom sztuki, których analityczne prace dotyczące nagrobków przedstawiają ogromną wartość w związku z poszczególnymi programami zdobniczymi, wpływami w sztuce etc. Często jednak ten ogromny, zgromadzony przez nich materiał, zostaje wykorzystany połowicznie - w publikacji badań wyniki analiz epigraficznych przedstawione są tylko częściowo lub nie występują w ogóle. Ogromny wysiłek włożony w badania terenowe spotyka się z niewykorzystaniem potencjału zebranego materiału, co powoduje potrzebę wykonania pracy w terenie i ponownego zebrania danych, w tym przypadku z nagrobków.

Schematy trzeci i czwarty dotyczą wartości informacji oraz szybkości ich przyswajania przez użytkownika (tu - w kontekście badacza). W przypadku badań epigraficznych analiza wartości poszczególnych inskrypcji dokonywana jest $\mathrm{z}$ reguły $\mathrm{w}$ zaciszu domowym, przy dokumentacji komputerowej oraz papierowej.

18 W domyśle zebrane w jednym miejscu. Edycje źródłowe, zbiory poszczególnych źródeł etc. Stuart Garner, „Personal knowledge management and student learning”, Journal of Business \& Economic Research 8(12) (2010): 43.

19 Jason Frand, Aura Lippincott, Personal Knowledge Management: A Strategy for Controlling Information Overload, 2002. Projekt dostępny online: http://www.anderson.ucla.edu/faculty/jason. frand/researcher/articles/info_overload.html, dostęp: 16 II 2017. 
Nie powinno się więc wyciągać wniosków w trakcie trwania badań terenowych. Naturalnym wydaje się, że wszelkiego rodzaju pomyłki w interpretacji nie powinny wówczas mieć miejsca. Ponownie, przenosząc tę kwestię na sprawy epigraficzne, ujednolicona baza danych inskrypcyjnych pozwalałaby na prowadzenie badań na materiale źródłowym, zgromadzonym w jednym miejscu oraz w sztywnej formie. Innymi słowy, badacz miałby dostęp do analogicznego materiału porównawczego z terenów np. Małopolski, Śląska, Pomorza Gdańskiego czy Wielkopolski. Umożliwiałoby to szerokie spectrum analizy inskrypcji o tym samym charakterze, występujących w różnych częściach Polski. W takim przypadku, zarządzanie informacją mogłoby przeistoczyć się w zarządzanie wiedząa ${ }^{20}$.

W obecnych czasach technologia posunęła się na tyle daleko, że pozwala na dużo szybsze, dokładniejsze i trwalsze obliczenia, analizę danych, a także ich przechowywanie czy udostępnianie. Mnóstwo materiałów źródłowych jest udostępnianych $\mathrm{w}$ zdigitalizowanej formie, dzięki czemu większa rzesza zainteresowanych ma możliwość dotrzeć do poszczególnych pozycji. Wydaje się tym samym, że koniunktura badawcza samoistnie się napędza. Świgoń zwraca uwagę, że wymiana informacyjna pomiędzy pracownikami naukowymi może przynieść nowe idee, a także ma znaczący wpływ na rozwój badawczy ${ }^{21}$. Przytacza ona jednak również badania dotyczące chęci wymiany informacji i dzielenia się wiedzą, wedle których to młodzi naukowcy są bardziej chętni do współpracy. Być może warto więc pochylić się nad stworzeniem takiej bazy epigraficznej, z której dobra korzystać będą zarówno młodzi, początkujący epigraficy, jak i doświadczeni badacze. Ponadto udostępnienie takich zbiorów byłoby również ułatwieniem dla badaczy innych dziedzin historii.

Podsumowując, dane epigraficzne, zebrane i prezentowane w obecnej formie, wydają się być wykorzystywane tylko częściowo. Zważając na problem ich rozproszenia, zarządzanie nimi, a także ich wykorzystywanie często są utrudnione. Ponadto pojawiają się pewne bariery informacyjne. Przytaczając choćby te związane z kulturą badacza - podejście indywidualistyczne zamiast kolektywnego, bariery technologiczne, związane z nieodpowiednim bądź niewystarczającym wykorzystaniem technologii informacyjnych ${ }^{22}$. To tylko część postulatów, którymi autor chciałby zaapelować o większą uwagę przy badaniach epigraficznych, a nade wszystko w związku z publikacją ich wyników oraz analiz. Istotne także wydaje się uwzględnienie kompleksowego modelu badawczego dla badaczy wszelkich dziedzin humanistycznych. Rokrocznie publikowane są prace z zakresu historii sztuki

20 Interesującą propozycję stworzenia modelu personalnego zarządzania informacją i wiedzą przedstawia Świgoń: Świgoń, „Personal Knowledge and Information Management - conception and exemplification", Journal of Information Science 39(6) (2013): 832-845.

${ }^{21}$ Świgoń, „Dzielenie się wiedzą wśród pracowników polskich uczelni”, w Praktyka i teoria informacji naukowej i technicznej 22(2-4) (2014): 67-69.

22 Świgoń, „Bariery informacyjne”, w Nauka o informacji, red. Wiesław Babik (Warszawa: Stowarzyszenie Bibliotekarzy Polskich, 2016), 464. 
dotyczące nagrobków, epitafiów oraz monumentów. Praktycznie w każdym przypadku badacze zwracają również uwagę na inskrypcje. Niestety jest to robione bardzo pobieżnie, ogólnie - co rzeczywiście jest zrozumiałe, ze względu na całkowicie odmienną metodologię badawczą, a także i sam cel badań par excellence. Jednakże ogromna praca włożona w już raz zebrany materiał często musi zostać ponowiona przez epigrafika, który chociażby dokumentując fotograficznie materiał badawczy, zbiera bądź kolacjonuje dane dotyczące inskrypcji. Warto więc zjednoczyć siły i umożliwić epigrafice ewolucję.

\section{Michał Dalidowicz \\ The perspective of epigraphic research and the concept of information management}

\section{Summary}

Epigraphy is one of the auxiliary sciences of history and yet it is still not fully used by scholars. The problem connects to the dispersion of research results and the form of their presentation. There are many independent researchers, representing different fields of science and studies that deal with inscriptions in their university and job activities. The only issue is that the results of their field researches are often presented in completely various ways, using a number of methods. That seems to be a bit problematic to use the metadata, because they regularly contain irrelevant data. Non-essential ones from the perspective of different scholar point of views. The aim of the article is to exhort scholars dealing with inscriptions (historians, historians of art, historians of culture, language etc.) to present the outcome of their researches in a way, every person interested in, could get what they need. E.g. while historian of art presents architectural programme of an epitaph, the inscription is barely mentioned, instead of being presented with the full analysis. One may find information about the art as itself, but semantics and semiotics of the inscription is not attached. The author of the article also asks to create an online version of all the inscription being gathered till nowadays, and those which are still in the progress of cataloguing. Many researchers does the enormous work, yet keeps their results for themselves, not publishing them to the broad circle of recipients. If creating such an instrument, scholars, especially students and beginners might find all interesting data at one place. Not only would it be useful, but also kept every collected data safe. 